\title{
How does WeChat's active engagement with health information contribute to psychological well-being through social capital?
}

\author{
Lianshan Zhang ${ }^{1} \mathbb{C} \cdot$ Eun Hwa Jung ${ }^{2}(\mathbb{D}$ \\ Accepted: 29 January 2021 / Published online: 18 February 2021 \\ (c) The Author(s), under exclusive licence to Springer-Verlag GmbH, DE part of Springer Nature 2021
}

\begin{abstract}
This study aims to examine how the users' engagement with health information benefits their well-being and to demonstrate the underlying mechanism of the relationships through bonding and bridging social capital. An online survey was conducted with 522 WeChat users in China. Structural equation modeling using the maximum likelihood of estimation was employed to test the study's hypothesized model. Bootstrapping methods were used to examine mediation effects. The results revealed that users' liking, sharing, and commenting behaviors were positively related to the bonding and bridging capital accumulated on WeChat. These two forms of social capital were also positively associated with users' psychological well-being, though bridging capital exerted more power in our research model. Moreover, both bonding and bridging capital mediated the relationship between WeChat affordances and psychological well-being. The findings shed new light on directions for leveraging mobile social media as an alternative means to bring about improvements in well-being in mobile-phone-saturated China. This is likely to be the first study that examines the mediating roles of bonding and bridging social capital on the relationship between users' health information engagement and users' psychological well-being. By providing robust findings by adopting the variable-centered approach in a health context, the findings of this study are promising for the extension and theoretical development of mobile social media research in the context of health information engagement.
\end{abstract}

Keywords Mobile social media $\cdot$ WeChat $\cdot$ Social capital $\cdot$ Psychological well-being $\cdot$ Affordance $\cdot$ Health information engagement

\section{Introduction}

With the enhanced functionality of smartphones, users increasingly strengthen their relationships and build new connections by interacting on mobile social media via various communication modes, including text messages, audio messages, and photographs. The diverse modes provide users with more opportunities not only to fortify their existing ties with family and close friends (associated with bonding social capital) but also to extend their social networks, connecting weak ties with geographically dispersed

Lianshan Zhang

lianshan@u.nus.edu

1 Department of Communications and New Media, National University of Singapore, Blk AS6, 11 Computing Drive, Singapore 117416, Singapore

2 School of Communication, Kookmin University, 77 Jeongneung-ro, Seongbuk-Gu, Seoul 02707, South Korea acquaintances and strangers (associated with bridging social capital) [20].

Previous researchers have already investigated the impact of social media on a user's social capital and personal wellbeing, though with mixed results [32]. For instance, some studies have demonstrated that social media use is conducive to an individual's social networking and the development of social capital as well as psychological well-being (e.g., [20, 21, 66]). Other empirical studies, however, have revealed that an individual's interactions with social media are related to increased feelings of depression, loneliness, and stress (e.g., [44, 48, 63]). A few studies have even suggested that social media use is not related, positively or negatively, to one's psychosocial outcomes (e.g., [58, 78]).

On the one hand, the controversial effects of social media may be due to the different influencing mechanisms. Instead of exerting a direct impact on personal well-being, social media may influence users' psychosocial outcomes through critical mediators, such as bonding or bridging social capital [13]. On the other hand, such inconsistent findings have 
been caused by the majority of extant research treating social media use as a relatively monolithic activity, even though people use social media for different purposes and pursue diverse activities (e.g., [7, 64]). Most previous studies examined social media users' behaviors by measuring their use of social media as a whole (i.e., time duration, intensity, network size), with no further differentiation and specification of the affordances usage, which limits the theoretical understanding of the effects of social media use $[6,80]$. Affordance is defined as an object's "action possibilities" or the opportunities that an interface feature provides for a certain interaction or action [52]. An object's affordance is different than the object itself. For example, a social media app is an object, but being able to like a photograph to show favorability toward other's posts is an action provided by the affordance of the "Like" button.

In particular, the use of social media and its outcomes (e.g., relationship development and psychosocial outcomes) have not been extensively explored in light of the unique features or affordances of mobile social media, especially outside of the Western context. China, for instance, as the country with the world's most active online social networking population, owned 1.6 billion mobile phone users, with more than $90 \%$ of them accessing social media via the most popular mobile application-WeChat ("Wei Xin" in Chinese) $[16,87]$. Evolving as a must-have app in China, WeChat possessed over 1.2 billion monthly active users by the third quarter of 2020 [73]. Therefore, it is important to investigate WeChat usage and its social and psychological implications in mobile-phone-saturated China.

WeChat has a unique feature, namely the availability of a public account or an official account. The public accounts allow corporations, news agencies, and the like to distribute various text, visual, and audio information, including vast health information updates, which enables users to quickly acquire customized and updated health information. In addition, the affordances of the "Like," "Share," and "Comment" buttons on WeChat allow users to easily communicate and interact with others by quickly expressing their opinions or supportiveness of others' posts on WeChat Moments (a function similar to Facebook's News Feed). Such engagement with health information is even more common during times of health crises and pandemics, such as the epidemic of H1NI and Ebola, as well as the outbreak of COVID-19 recently $[17,67]$. In addition to facilitating public health information dissemination, noticeably, users' engagement with the health-related posts on social media can also serve as a way of socializing [50]. Although studies have found that users have extensively adopted WeChat and actively engage with health-related information as part of their social interactions [86], to date, almost no research has examined the social outcomes (e.g., social capital) of their active engagement with health information on the site by investigating specific features, such as "Like," "Share," and "Comment." In this article, the phrase active engagement with health information means using one of these three specific features-Like, Share, or Comment-or a combination of these features, to interact with the health information found on WeChat [86].

Hence, given the growing prevalence of active engagement of health-related information on mobile social media and its potential benefits for psychosocial outcomes, this study examines users' active engagement with health information in pursuit of the following three goals. First, unlike previous studies, which treated social media usage or mobile phone usage as a monolith, this study aims to uncover how the use of particular affordances is related to users' social capital and psychological well-being, particularly in health contexts. Second, this study strives to assess the mediating role of social capital in a relationship between mobile social media engagement and psychological outcome. Third, this study seeks to distinguish between the mediating effects of two types of social capital: bonding and bridging [61]. Examining these two types of social capital allows for a more nuanced comprehension of which affordance leads to which form of social capital and how distinct categories of social capital contribute to the psychological well-being of Chinese WeChat users. Therefore, this study helps to explain the different forms of social capital fostered by mobile social media's affordances and to describe the practical implications of employing mobile social media in a health context to contribute to Chinese users' well-being.

\section{Literature review}

\subsection{Social media uses and social capital}

Social capital is a multidimensional construct [42]. At the individual level, social capital is conceptualized as a valuable asset in an individual's daily life, which can be activated and used for, among other things, job attainment, better health, and civic engagement $[11,41,42]$. Drawing on Granovetter's research on tie strength [25, 26], Putnam [61] distinguished between two forms of social capital, namely bonding social capital and bridging social capital, which are closely linked to strong and weak ties, respectively. Bonding generates strong group solidarity that provides an individual with emotional support within dense social ties, while bridging facilitates one's development of a broader identity and reciprocity (i.e., a feeling of mutual benefit and goodwill) with other people from different backgrounds who can offer novel information and diverse resources [25, 26].

Social capital, both bonding and bridging, is accumulated through an individual's investment in interactions with the social network [42]. Social media applications provide ideal 
platforms for building and cultivating a sense of connection with existing networks, especially for creating weak ties with geographically distant people at a low transaction cost [20]. However, most of the extant studies on social media examined social media use in an overly simplistic way by treating it as a monolith, failing to distinguish among users' different patterns of usage that involve diverse functions employed for distinct purposes [6]. Indeed, social media is an omnibus channel consisting of various functions, and it is assumed that the effect of social media use is differentiated from the function it serves.

Burke and colleagues [8] found that although overall Facebook usage was associated with participants' social capital, participants who were more engaging in Facebook activities (e.g., status updates and photograph posts) reported higher levels of bonding social capital. Ellison and colleagues [21] also demonstrated that the specific Facebook activities that are publicly viewable and therefore signal attention (e.g., Wall posts, tags, comments on a friend's post) are strong predictors of bridging social capital. This finding suggests that users who are more inclined to engage in certain social media activities may be more likely to capture social capital benefits. On the contrary, prior studies found that the uses of social media for entertainment and diversion (i.e., games, passive consumption) were not related to or negatively associated with bonding or bridging social capital (e.g., $[8,27,68])$. Such findings imply that individuals' psychosocial outcomes are derived not from the technology per se but from the specific ways in which people use the technology. Theoretically, the uses and gratifications perspective contends that people use social media differently due to their disparate motivations [64]. That is, individuals tend to use different social media features to gratify their distinct psychological needs. More importantly, different motivations of social media use leading to the disparate selection of and engagement with social networking activities may also yield different media effects [62]. Along with such theoretical reasoning, empirical studies have also indicated that the motives of social interaction and building self-agency are significant triggers of using the "Like" and "Share" features for health-related information engagement on social media [86]. Therefore, it is reasonable to speculate that different usages of the affordances on a social media application, which are prompted by varying user motivations, can make a difference in subsequent individuals' social and psychological outcomes.

As such, this study adopts the variable-centered approach [51] to unpack particular activities allowed by specific features to better elucidate the mechanism through which affordance-enabled behaviors relate to certain forms of social capital and psychological well-being. Specifically, the variable-centered approach isolates the psychological effects of key technology variables from the medium [70]. This approach argues that different variables (i.e., affordances) embody different values, which allows researchers to attribute the different effects between two media to specific features [70]. Guided by the variablecentered approach, we extend the line of studies on social media use to focus on users' active engagement with health information.

\subsection{Active engagement with health information}

Engagement in a virtual community has been conceptualized as a user-initiated action that facilitates user experiences of co-creation with others that may lead to some consequences such as satisfaction and empowerment [4]. In social media contexts, engagement can be generally identified as an individual's interaction with media from behavioral, cognitive, and emotional aspects [4, 36]. Guided by the variable-centered approach, this study investigates the engagement through the behavioral aspect with online content or "click-based interactions" [36] to capture the nature of users' specific interactions with the affordances. Though there are many other functions on mobile social media, the three features encompassed by this paper's definition of active engagement-Like, Share, and Comment-are among the most frequently used on WeChat, representing the most common affordances available for study and a large proportion of user behavior on mobile social media [23, 82]. The examination of these three interactive features (i.e., Like, Share, Comment) also bears broader practical implications as they are applicable to online behavioral engagement on other social media contexts like Facebook and YouTube [36].

The reason we focused on health information engagement was twofold. First, recent studies have found that WeChat is a promising platform for health communication, and users' health-related information acquisition and engagement pervade the site (e.g., [81, 86-88]). Indeed, mobile social media have become popular as a source of health information and provide active environments for health education and promotion due to its capacity for interactivity [45]. Given this great potential of health communication, it is worth investigating how these interactivity affordances (i.e., Like, Share, Comment) in a health context facilitate one's social network development and its contribution to well-being. Most importantly, previous research on the impact of social media employed an entirely content-free approach to investigating participants' social media usage, which limited the extension and theoretical development of social media research [7]. Therefore, this study especially defines the content of user engagement: health information on WeChat. 


\subsection{Active engagement with health information and social capital}

Lin [42] defined social capital as an "investment in social relations" (p. 19), which accentuates the significance of active effort in committing to and sustaining personal networks. In other words, the frequency of interactions, as well as the length and depth of messages, serves as a signal of a relationship's value $[19,21]$. Spending time and effort in using social media for networking is similar to other methods of accumulating social capital [75]. Scholars have indicated that, compared to passive content consumption, the use of the "Like," "Share," and "Comment" features involves a higher level of cognitive effort and attention in the process of online communication [1]. That is to say, the relatively effortful communication modes categorized as active engagement-which demand that individuals devote more time and premeditated thought than required for passive activities like browsing - serve as distinct forms of investment in social interaction, signaling the relative value of different relationships.

Several theoretical underpinnings help demonstrate the positive relationship between a user's active engagement through the acts of liking, sharing, and commenting with health information and the accumulated social capital. First, the click of the "Like" button carries an array of potential social meanings. In particular, Hayes et al. [29] conceptualized lightweight social media feedback cues (e.g., Like, Favorites) as paralinguistic digital affordances (PDAs) similar to forms of phatic communication. The phatic communication comprising of communicative behaviors such as waving or saying "hey" in offline settings is argued signals sociability while having no or little substantive information exchanges [47]. Similar to such vague communicative behaviors, clicking the "Like" button is generally deemed as a social response to a particular friend's social media content signaling one's attention and usually involving positive connotation [29]. Hence, liking behavior also serves phatic purposes and can generate comparable social benefits to phatic communication in face-to-face contexts $[9,49]$.

In addition to exhibiting an extra attention paid to a given social relationship that is worthy of a social response, the nonverbal cue of the "Like" button provides receivers with a greater sense of social validation [24]. For instance, a click of the "Like" button indicates one's explicit agreement and endorsement of another person's post, providing supportbased feedback [23]. This way of expressing endorsement is considered to be particularly prominent in the health context because of the increased concern about the quality of health information that is directly related to one's health [88]. For example, in the face of a pandemic, when so much uncertainty and misinformation are in the air, liking a particular health post can be used in a faithful manner to address properties or the quality of the posted content and to convey content-based messages such as "this is accurate information" or "I approve of this quality post" [29, 71]. This offers receivers a socially positive connotation and a feeling of approval from senders, which is beneficial for generating positive social outcomes [71].

The use of the "Like" button is also effective in expressing relational-based sentiments such as "I support you" or "I care about you" to nurture social bonds [71]. For example, Lee and colleagues [40] found that clicking Like to endorse others on social media helps users show support to ones they care about, and maintaining interpersonal connectivity was the primary motive for liking behavior. More importantly, liking a friend's health-related post not only is targeted interaction that singles out a particular friend, but is also public viewable to a group of common friends of senders and receivers. This creates a sense of social presence, a quality of "being there" of a broad network [12], which is beneficial for relationship maintenance particularly for ties that are physically separated [74]. As such, the engagement of liking a friend's health-related post functions a time-saving and low-cost way in maintaining relationships with their network of both strong and weak ties [29, 71], which suggests the following:

$\mathrm{H} 1 \mathrm{The}$ frequency of liking health-related information is positively related to (a) bonding and (b) bridging social capital on WeChat.

Sharing health information on social media, either privately to a particular friend or publicly to one's networks of friends, is an effective way to express a user's various forms of support, both informational and emotional support [43, 87]. On the one hand, sharing health information can provide the receivers with more access to information than they would ordinarily have without this social media engagement. Especially in an era of information overload and widespread misinformation on social media, highlighting what is useful and trustworthy can benefit the receiver as well as enhance the relationship between the sender and receiver [46]. In fact, one of the primary motivations of sharing health information on WeChat is to surveil and dispel health-related rumors and fake news [86]. Liu and colleagues [43] also indicated that sharing health information is an act of distributing informational resources and support incorporating social and altruistic elements. Thus, to some extent, the health information sharing behavior facilitates social capital not only by means of social purposes but also by providing information aid and instrumental resources.

Apart from offering informational and emotional support, previous studies have indicated that self-disclosure such as broadcasting plays a beneficial role in relationship building $[38,84]$. Self-disclosure is defined as the act of revealing 
personal information to others [76]. User's sharing behavior can be considered a form of self-disclosure because such broadcasting produces observable information and content that reveal one's personal thoughts and feelings. Considering this, sharing or reposting health-related posts can build relationships through regular exposure to social ties. Even if an individual's initial intent of sharing health information is to provide relevant information to family and close friends to reinforce the strong-ties relationship, the one-tomany interaction on these sites allows casual colleagues and acquaintances to consume the information, as well, which can be useful for developing the weak-ties relationship [13]. More importantly, as Tichon and Shapiro [72] stated, the social benefits of self-disclosure are largely derived from the supportive reactions from others. Sharing health-related posts thus offers a mechanism for obtaining supportive resources through receiving supportive responses from others, similar to how disclosing personal information leads to greater support and social capital [37]. Further supporting this reasoning in a health context, Oeldorf-Hirsch and colleagues [53] found that frequent sharing of tracked health information and receiving feedback from network members on social network sites contributed to users' all forms of supportive resources. Because WeChat users can not only share health-related information directly to a particular friend or family member but also to more distant acquaintances publicly through WeChat Moments, the opportunity to boost the users' bonding and bridging social capital on WeChat is enhanced. Hence, this study postulates that:

H2 The frequency of sharing health-related information is positively related to (a) bonding and (b) bridging social capital on WeChat.

In light of Lin's social capital theory [42], investment in social relations is essential to build up social capital. Together with this, people on social media tend to rely on visible signals to infer the strength of a given relationship [19]. In addition to Like and Share, commenting is another typical "social grooming" activity that signals the sender's willingness of committing to certain social interactions [19]. This is also to say, explicitly responding to another user's post via activities like commenting or replying is an effective way to indicate that one has made an active effort in paying special attention to at least some aspects of another individual's daily life [21]. In particular, purposefully spending time to formulate a nuanced and informative message in responding to another person's health-related posts is argued as an effortful form of interaction that requires certain degrees of deliberation and cognitive thinking [1,54]. As such, commenting represents the signaler's value placed on a given relationship and the desire for more closeness or intimacy than the signaler would want without such social interactions [19, 57], which is conducive for bonding social capital accumulation.

In addition to fostering social bonds by devoting time and effort to a given relationship, providing feedback or replying to others through commenting can activate a sense of reciprocity [6], which is conceptualized as a key facet of social capital [61]. For example, Ellison et al. [21] indicated that users who respond to the sender will expect that the receiver and others in their network will do so in the future. They then found that the behavior of commenting evokes norms of reciprocity (e.g., the extent to which individuals engage in exchanges for mutual benefit and goodwill of individuals or communities), which is critical in augmenting bridging social capital. Furthermore, commenting on a health-related post that is simultaneously visible to other network members is a form of mass personal communication [55]; thus, commenting is the means through which public exchange and open dialogue develop on social media. In this regard, feedback and message exchanges via the Comment feature might prompt users' cognitive processing regarding the posted health issue [54] and provide them with heterogeneous perspectives and opinions, enhancing their outwardlooking and the feeling of social connectedness with others in the community. For example, a sentiment analysis study demonstrated that users in a Facebook diabetes community frequently commented on posted health information for discussion and experiences exchanges, giving rise to their sense of belonging in a broader community [35]. More importantly, through the act of commenting, users are signaling to their social networks publicly that they are open to others' reciprocal messages and replies, which contributes to future social interaction and the accumulation of more social capital from a broad range of connections, including both strong ties and weak ties [7]. Therefore, it is likely that frequent commenting on health-related information is beneficial for advancing both bonding and bridging social capital; thus, the following hypothesis is posited:

H3 The frequency of commenting on health-related information is positively related to (a) bonding and (b) bridging social capital on WeChat.

\subsection{Social capital and psychological well-being}

In addition to examining the link between social media uses and social capital, the extant research has thoroughly demonstrated that social capital is positively related to psychological well-being, a key aspect of the psychosocial effect of social media use. Psychological well-being generally refers to individuals' subjective judgments and assessments about the functionality and meaningfulness of their lives (i.e., purpose in life, autonomy, positive relationships with others) $[10,18]$. People who have maintained high-quality 
friendships and broader social networks usually feel better about their lives [85]. A growing body of empirical research has confirmed the link between the cultivated social capital and enhanced psychological well-being (e.g., [10, 31, 39]). For instance, Helliwell and Putnam [31] found that social capital is strongly related to both physical health and subjective well-being. In online settings, Ang et al. [2] found that the friendships and relationships built through computermediated communication (CMC) gratify individuals' psychological needs with a greater sense of satisfaction with their lives. Zhan et al. [85] also demonstrated that social benefits obtained from social media interactions positively predicted enhanced life satisfaction. Similarly, Wang et al. [79] found that college students' social media uses in Singapore were positively associated with both strong and weak ties that enhanced personal well-being. Guo et al. [27] revealed that social media uses, both for social and for informational purposes, were positively related to Chinese international students' social capital and social network building, which further contributed to their psychological well-being.

Despite the positive relationship between social capital and psychological well-being as found in prior studies, relatively less attention has been paid to whether bonding and bridging social capital are equivalently important in contributing to one's psychological well-being. In other words, the nuanced impacts of these two forms of social capital on psychological well-being need to be examined. In addition, previous studies have yielded mixed results about the role of different forms of social capital on well-being; some studies found that bridging social capital is especially significant in predicting one's psychological well-being (e.g., [79]), whereas others found only bonding social capital is positively related to an individual's well-being (e.g., [56]). In light of these gaps and contradictions, this study has posed two additional hypotheses to closely examine how the two forms of social capital are related to one's psychological well-being:

H4 Bonding social capital on WeChat is positively related to psychological well-being.

H5 Bridging social capital on WeChat is positively related to psychological well-being.

\subsection{The mediating role of bonding and bridging social capital}

This study strives to make explicit the two-step relationship that links three elements: social media active engagement, social capital, and psychological well-being. Put another way, one underlying pathway between active engagement and improved psychological well-being is likely to be mediated by the access to bonding and bridging social capital.
In particular, Valkenburg and Peter [77] pinpointed that the extant studies have over-emphasized the direct effect of Internet technologies on well-being. Previous studies' mixed results concerning the relationship between social media use and well-being may partly be caused by the research overlooking the underlying mechanisms of the associations. Thus, to uncover the nuanced dynamics, this study proposed a two-step model to investigate the relationship between WeChat users' active engagement with health information and user's psychological well-being, highlighting the mediating roles of bonding and bridging social capital.

Several empirical studies have supported the mediating role of social capital in the relationship between social media use and well-being. For instance, a two-wave panel examination in Hong Kong revealed that different uses of mobile social media (i.e., communicative use, self-disclosure, friending) indirectly contributed to enhanced psychological well-being via the direct positive effect on bonding and bridging social capital [13]. Their study also found that bonding social capital exerted more power than bridging social capital in predicting one's psychological well-being. Similarly, Pang [56] demonstrated that social media used for social purposes exerted an indirect effect on one's psychological well-being through the increased level of bonding and maintained social capital. Sum et al. [68] found that using the Internet for communication and informationseeking (vs. entertainment, commerce, finding new people) was positively related to senior citizens' personal well-being through the mediation of social capital. In light of this line of research, it is expected that a user's active engagement on social media, involving the user's investment in both strong and weak ties, is beneficial for the development of one's social capital, which ultimately enhances one's psychological well-being. Thus, the following hypotheses investigate the mediating roles of bonding and bridging social capital:

H6 Bonding social capital on WeChat mediates the relationship between active engagement with health information(a) liking, (b) sharing, and (c) commenting — and psychological well-being.

H7 Bridging social capital on WeChat mediates the relationship between active engagement with health information-(a) liking, (b) sharing, and (c) commenting-and psychological well-being.

Taken together, as shown in Fig. 1, this study proposed a hypothesized model, based on the abovementioned seven hypotheses, to examine how the use of different affordances that are available on the WeChat mobile social media application predicts users' bonding and bridging social capital and provides a pathway linking active engagement with health information to one's psychological well-being. 
Fig. 1 Hypothesized model

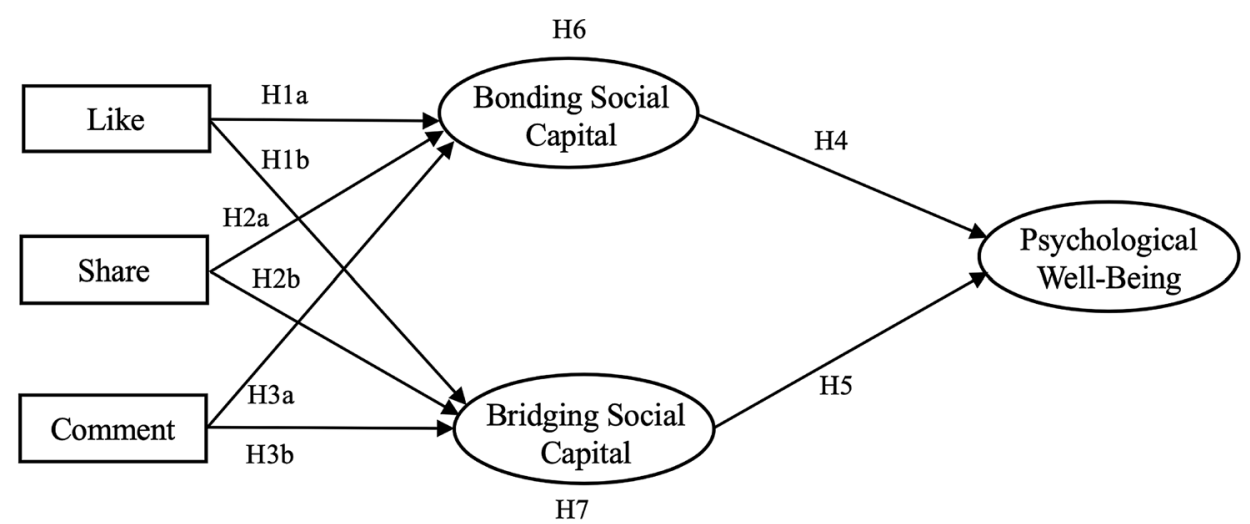

\section{Method}

\subsection{Participants}

An online survey was conducted by a professional online research company in China, namely Wenjuanxing (https ://www.wjx.cn), from September 23, 2017, to October 3, 2017. Wenjuanxing provides a national sampling service that consists of a sampling pool of more than 2.6 million registered respondents with diverse demographic characteristics. The data were obtained through convenience sampling by randomly selecting participants who met our survey inclusion criteria (e.g., WeChat users) from the company's nationwide online panels. In an attempt to capture WeChat users' behaviors across different user groups, the survey company was requested to recruit an equal gender ratio, which largely reflects the current internet users' gender structure in mainland China [15]. In addition, considering that Chinese elderly adults are found to be active in online health-related information engagement $[43,81]$, the survey company was requested to particularly recruit more senior participants aged 50 years and above, although such an older population is relatively scarce in online panels in China. The survey company used several tactics in the process of administering the questionnaires to eliminate invalid cases (e.g., attention-check questions, detection of repeat Internet Protocol [IP] addresses, and surveillance). After eliminating invalid questionnaires, in total 522 valid responses were obtained through the company's online panels. Participation was voluntary, and the survey questionnaires were completely anonymous. Participants were all WeChat users and were provided with vouchers as incentives after completing the questionnaire. Of the 522 respondents, the mean age was 37.98 ( $S D=9.80$, ranging from 20 to 83 years old); $49.8 \%$ were male; $70.5 \%$ had received a college degree or higher education; $73.9 \%$ had a monthly personal income of around 1,000 USD or more (see Table 1 for demographic descriptives of the participants).
Table 1 Demographic information of the participants $(N=522)$

\begin{tabular}{llc}
\hline Variables & Categories/range & $\%$ or $M(S D)$ \\
\hline Age (years) & $18-30$ & $26.6 \%$ \\
& $31-49$ & $62.1 \%$ \\
Gender & 50 and above & $11.3 \%$ \\
Education & Male & $49.8 \%$ \\
& Female & $50.2 \%$ \\
& Less than high school & $5.4 \%$ \\
& High school & $10.2 \%$ \\
& Some college or technical & $13.9 \%$ \\
Monthly income & school degree & \\
& College and above & $70.5 \%$ \\
& CNY1999 and less & $3.6 \%$ \\
& CNY 2000 to CNY3999 & $10.2 \%$ \\
& CNY 4000 to CNY5999 & $12.3 \%$ \\
& CNY 6000 to CNY7999 & $40.4 \%$ \\
& CNY 8000 to CNY9999 & $24.3 \%$ \\
General health status & CNY 10,000 and above & $9.2 \%$ \\
& 1 (poor) to 5 (excellent) & $4.20(.55)$ \\
\hline
\end{tabular}

\subsection{Measures}

\subsubsection{WeChat active engagement with health information}

Developed from prior literature $[1,86]$, users' active engagement with health information was measured by the frequency of usage of the three designated WeChat features (Like, Share, and Comment) to engage with health-related posts on a 4 -point scale $(1=$ Never, $4=$ Often $)$. To avoid possible confusions, we included a sentence in the questionnaire to provide participants with the definition of the health-related post: "The health-related post on WeChat in the current questionnaire includes but is not limited to the information concerning: health management and education (e.g., exercise, abstinence from drinking and smoking, diet, nutrition, mental health), a particular illness or symptom, prescription drugs, diseases diagnosis, treatments, and 
prevention, as well as correction for health misinformation and rumors."

Specifically, participants were asked to estimate their usage of the "Like" button with the survey question, "How often do you 'Like' a health-related post on WeChat?" $(M=2.92, S D=0.84)$. Similarly, participants' usage of the "Comment" button was assessed by asking, "How often do you comment on or reply to a health-related post on WeChat?" $(M=2.59, S D=0.82)$. For the frequency of sharing behavior, participants were asked to report their usage involving two broadcast levels (i.e., "How often do you use features on WeChat to share or repost a healthrelated post with a particular friend?"; "How often do you share or repost a health-related post on WeChat Moments?"; $M=2.81, S D=0.70, r=0.68, p<0.001)$. It is worth noting that although sharing behavior was measured by two items, in our structural model, it was treated as an observed variable defined by its causal indicators, rather than a latent variable that determines its effect indicators [3]; therefore, it was computed as an index influenced by the two causal indicators in the structural model. In this sense, a difference in any one of the causal indicators (e.g., two items) would cause a change in overall sharing behavior rather than the reverse that an increase in sharing behavior requires a simultaneous increase in both two indicators.

\subsubsection{Bonding and bridging social capital on WeChat}

To examine the degree to which participants perceived they had access to social capital on WeChat, eight items were adapted from the Internet Social Capital Scales (ISCS) [83], respectively, for bonding social capital (e.g., "When I feel lonely, there are several people I can call to talk to on WeChat.") and bridging social capital (e.g., "Based on the people I interact with on WeChat, it is easy for me to hear about the latest news and trends."). Participants responded using a 5-point Likert scale (1=Strongly Disagree, 5= Strongly Agree), with wording changed to fit the WeChat context so that all respondents would have the same frame of reference applicable to the context of the study. The scales of bonding social capital (Cronbach's alpha $=0.82$, $M=3.64, S D=0.49$ ) and bridging social capital (Cronbach's alpha $=0.84, M=3.82, S D=0.50$ ) were reliable (see all the measured items in Table 2).

\subsubsection{Psychological well-being}

To evaluate the extent to which the study participants assessed various important domains of their functioning (e.g., social relationship, feeling of competence, meaning in life), eight items were adopted from the Psychological WellBeing Scale [18]. Respondents were asked to report their level of agreement with eight subjective statements about the meaningfulness and functioning of their lives (e.g., "I lead a purposeful and meaningful life." "My social relationships are supportive and rewarding.") on a 5-point Likert scale $(1=$ Strongly Disagree, $5=$ Strongly Agree ; Cronbach' $\mathrm{s}$ alpha $=0.86, M=4.06, S D=0.47$ ).

\subsubsection{Control variables}

As previous research has indicated, a user's overall social media usage and network size are closely related to the user's social capital and psychological well-being (e.g., [13, 20]). It is necessary to control these variables to isolate the unique associations among the investigated variables.

3.2.4.1 WeChat usage WeChat use was measured using two components: intensity and frequency. Intensity measurements were modified from instruments defined by Ellison et al. [20]. A participant's WeChat intensity $(M=4.09$, $S D=0.55$, Cronbach's alpha $=0.84$ ) was measured by six statements (e.g., "WeChat is part of my everyday activity." "WeChat has become part of my daily routine.") on a 5-point Likert scale $(1=$ Strongly Disagree, $5=$ Strongly Agree $)$. As to the frequency of WeChat use $(M=3.48, S D=0.87)$, participants were asked to indicate their frequency on a 5-point scale by selecting from predefined time ranges: $1=$ rarely use (less than $30 \mathrm{~min}$ per day); $2=$ sometimes $(31-60 \mathrm{~min}$ ); $3=$ often $(61-90 \mathrm{~min}) ; 4=$ frequently use $(91-150 \mathrm{~min})$; $5=$ always (more than $150 \mathrm{~min}$ ).

3.2.4.2 WeChat network size Participants were asked to estimate approximately how many WeChat contacts they had. The scores were highly skewed $(M=179, M d n=120$, $S D=281.16$, Skewness $=6.33)$; therefore, the scores were transformed using the natural logarithm $(M=4.69$, $M d n=4.79, S D=0.83$, Skewness: -0.19 ).

3.2.4.3 Demographics Social and demographic characteristics, including age, gender, education level, monthly income, and physical health status, were also measured as control variables.

\subsection{Data analyses}

In order to examine the hypothesized model with several pathways between the independent and dependent variables, structural equation modeling (SEM) using the maximum likelihood of estimation was employed using lavaan package in $\mathrm{R}$ (lavaan is an open-source package, see http:// lavaan.ugent.be/ for more information). We first conducted a confirmatory factor analysis to examine the measurement model, and then, we tested the hypothesized model and the proposed hypotheses. To examine the mediation effects, 
Table 2 Confirmatory factor analysis of model variables

Item

Bonding social capital $(\alpha=.82)$

When I feel lonely, there are several people I can call to talk to on WeChat

If I have severe financial difficulties, I know there is someone that can help me on WeChat

I am most comfortable communicating with people and groups who share my values and beliefs on WeChat .777

There are several people on WeChat I trust to solve my problems

There is someone on WeChat I can turn to for advice about making very important decisions

The people I interact with on WeChat would be good job references for me

I do not know people on WeChat well enough to get them to do anything important (reversed)

I have the ability to organize my group of friends on WeChat to fight injustice

Bridging social capital $(\alpha=.84)$

Based on the people I interact with on WeChat, it is easy for me to hear about the latest news and trends

Interacting with people on WeChat makes me curious about things and places outside of my daily life

I interact with people on WeChat who are quite different from me

Interacting with people on WeChat makes me feel like a part of a larger community .579

On WeChat, I come into contact with new people all the time $\quad .764$

Interacting with people on WeChat reminds me that everyone in the world is connected .615

I am willing to spend time to support the general WeChat community's activities .673

Psychological well-being $(\alpha=.86)$

I lead a purposeful and meaningful life

My social relationships are supportive and rewarding $\quad .644$

I am engaged and interested in my daily activities $\quad .627$

I actively contribute to the happiness and well-being of others .693

I am competent and capable in the activities that are important to me .619

I am a good person and live a good life $\quad .584$

I am optimistic about my future $\quad .753$

People respect me .688

Standardized factor loading estimates are reported. $\alpha=$ Cronbach's alpha. $N=522$

bootstrapping methods [28] were used with cases of 522 and resamples of 5,000 to generate the path confidence interval.

\section{Results}

\subsection{Measurement model}

The measurement model yielded a good model fit: $\chi^{2} /$ $\mathrm{df}=1.77(<3), p<0.001$, comparative fit index $(\mathrm{CFI})=0.96$, Tucker-Lewis index $(\mathrm{TLI})=0.94$, root-mean-square error of approximation $($ RMSEA $)=0.03$, and standardized root mean square residual $(\mathrm{SRMR})=0.04$.

The widely used combinational rules were applied to evaluate the relative goodness of fit of the measurement model and the hypothesized model: (a) the Chi-square to the degrees of freedom ratio $\left(\chi^{2} / \mathrm{df}\right)$ should be less than 3; (b) CFI $>0.95$, and SRMR $<0.09$, or, alternatively, RMSEA $<0.05$, and SRMR $<0.06$ [33]. In addition, considering the factor structure-meaning no low-factor loadings (below 0.5) were found [22]—we accepted the measurement model, as shown in Table 2.

\subsection{Structural model}

Table 3 shows bivariate correlations of all variables. Considering the significant correlations between control variables and main variables (active engagement, social capital, and psychological well-being), it is necessary to account for the effects of control variables in the structural model to rule out potential confounding effects. Hence, similar to prior studies $[11,13,56]$, the structural model of this study was conducted by controlling the social demographics (e.g., age, gender, education, income, health status) and general WeChat usage (e.g., WeChat use frequency, WeChat intensity, and WeChat network size) on outcome variables of bonding and bridging social capital, as well as psychological well-being. The initial specified model showed an acceptable model fit: $\chi^{2} /(507)=2.03$, $p<0.001, \mathrm{CFI}=0.94 ; \mathrm{TLI}=0.92, \mathrm{RMSEA}=0.04$, 
Table 3 Correlation Coefficients among All Variables Used in the SEM Analysis (a)

(b)

(c)

(d)

(e)

(f)

\begin{tabular}{lllllll}
\hline (a) Frequency of liking & - & & & & & \\
(b) Frequency of sharing & $.58^{* * *}$ & - & & & & \\
(c) Frequency of commenting & $.56^{* * *}$ & $.51^{* * *}$ & - & & & \\
(d) Bonding social capital & $.35^{* * *}$ & $.32^{* * *}$ & $.33^{* * *}$ & - & & \\
(e) Bridging social capital & $.46^{* * *}$ & $.40^{* * *}$ & $.41^{* * *}$ & $.53^{* * *}$ & - & \\
(f) Psychological well-being & $.46^{* * *}$ & $.37^{* * *}$ & $.34^{* * *}$ & $.58^{* * *}$ & $.61^{* * *}$ & - \\
Age & .01 & $.09^{*}$ & -.03 & $-.09^{*}$ & .01 & -.01 \\
Gender & -.08 & $-.09^{*}$ & $-.10^{*}$ & -.04 & $-.10^{*}$ & $.11^{*}$ \\
Education & .08 & .07 & .07 & .04 & .06 & $.10^{*}$ \\
Income & $.15^{* *}$ & $.13^{* *}$ & $.19^{* * *}$ & $.22^{* * *}$ & $.21^{* * *}$ & $.18^{* * *}$ \\
Health status & -.04 & -.07 & -.04 & .02 & .01 & $.21^{* * *}$ \\
WeChat use frequency & $.35^{* * *}$ & $.32^{* * *}$ & $.29 * * *$ & $.33^{* * *}$ & $.38^{* * *}$ & $.26^{* * *}$ \\
WeChat intensity & $.34^{* * *}$ & $.32^{* * *}$ & $.28^{* * *}$ & $.37 * * *$ & $.45^{* * *}$ & $.28^{* * *}$ \\
WeChat network size & $.10^{*}$ & .07 & $.18^{* * *}$ & $.23^{* * *}$ & $.24 * * *$ & $.17^{* * *}$ \\
\hline
\end{tabular}

SEM $=$ structural equation modeling. Gender: $1=$ male, $2=$ female. $N=522$

${ }^{*} p<.05 ; * * p<.01 ; * * * p<.001$
SRMR $=0.05$. However, among the eight control variables predicting psychological well-being, five paths from age ( $\beta=0.018, p=0.685)$, education $(\beta=0.066, p=0.165)$, WeChat frequency $(\beta=0.012, p=0.729)$, WeChat intensity $(\beta=-0.044, p=0.512)$, and WeChat network size ( $\beta=-0.008, p=0.841)$ to psychological well-being were not significant. Thus, these five paths were removed to establish a more parsimonious model. All other covariate paths were kept. The re-specified model had a good fit: $\chi^{2} /(512)=1.74, p<0.001$, CFI $=0.96$; TLI $=0.94$ and RMSEA $=0.03$, SRMR $=0.04$. The Chi-square test results indicated a significant improvement with the respecified model: $\Delta \chi^{2}(5)=46.39, p<0.001$. In addition, the respecified model generated a smaller Akaike information criterion (AIC: 29,853.22) and Bayesian information criterion (BIC: 30,300.275) compared to the initial model (AIC: 29,993.75; BIC: 30,396.49), indicating that the respecified model has a better parsimonious fit.

\subsection{Hypotheses testing}

H1 through $\mathrm{H} 3$ predicted that the frequency of liking, sharing and commenting on health information would be positively related to WeChat bonding and bridging social capital. As shown in Fig. 2, the more users clicked the "Like" button for a health-related post, the greater their perceived bonding $(\beta=0.25, p<0.001)$ and bridging social capital $(\beta=0.35$, $p<0.001)$ on WeChat; hence, H1a and H1b were supported. Similarly, frequent commenting on health-related information on WeChat was positively associated with WeChat users' perceived bonding $(\beta=0.18, p<0.01)$ and bridging social capital $(\beta=0.15, p<0.01)$, supporting H3a and H3b. Unlike the use of features of "Like" and "Comment," the results revealed that there was no significant relationship between sharing and bonding social capital $(\beta=0.11$, $p=0.09$ ), although frequent sharing of health-related content on WeChat was a significant predictor of bridging social capital $(\beta=0.16, p<0.01)$. Thus, H2b was supported, but
Fig. 2 Final model with standardized path coefficients and R squares. Notes Dashed line indicates a nonsignificant relationship. The covariances between all exogenous factors (e.g., controls) and coefficients with control variables were not presented for the purpose of clarity. $* p<.05$; ** $p<.01$; $* * * p<.001$

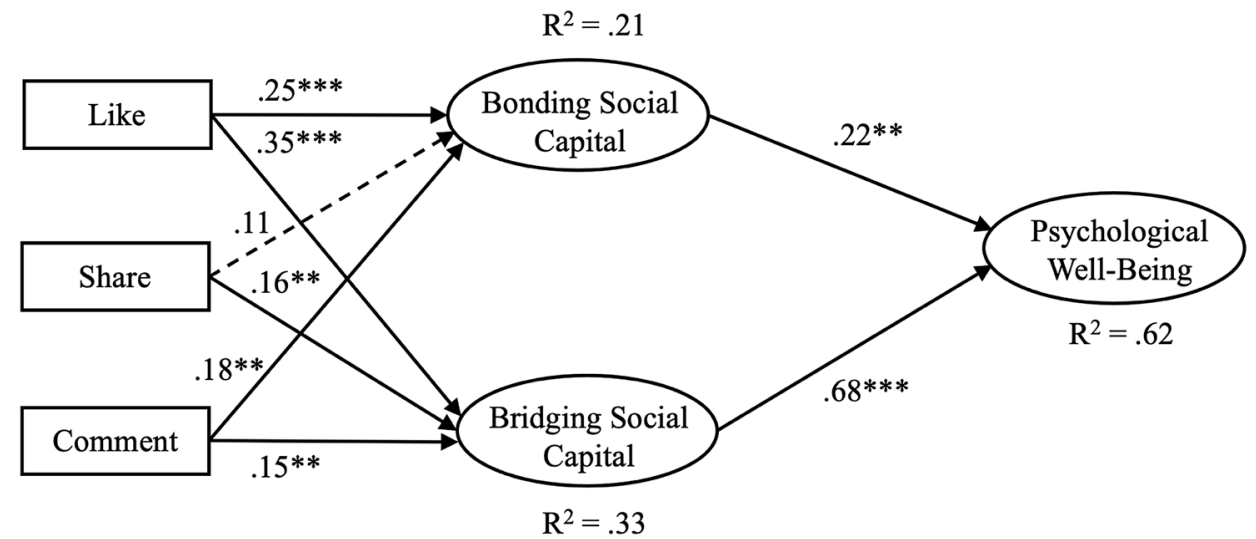


not H2a. In addition, both bonding social capital $(\beta=0.22$, $p<0.01)$ and bridging social capital $(\beta=0.68, p<0.001)$ were positively associated with individuals' psychological well-being, though bridging social capital exerted a stronger power in our model. Therefore, H4 and H5 were supported.

As predicted, the bootstrapping results indicated that bonding social capital $(b=0.08, \mathrm{SE}=0.02,95 \%$ CI [0.04, $0.13])$ and bridging social capital $(b=0.26, \mathrm{SE}=0.03,95 \%$ CI $[0.20,0.33])$ mediated the relationship between active engagement with health information and psychological well-being, supporting $\mathrm{H} 6$ and $\mathrm{H} 7$ (see Table 4 for the summarized indirect relationships). Overall, our hypothesized model explained $21.44 \%$ of the variance of bonding social capital, and $33.28 \%$ of the variance of bridging social capital, as well as $62.39 \%$ of the variance of psychological well-being.

\section{Discussion}

\subsection{Key findings}

Drawing upon the social capital literature and the variablecentered approach, this study examined the structural connection between WeChat-specific affordances uses, one's social capital, and one's psychological well-being. The study also assessed the underlying mechanism of these associations in a health context. Our hypothesized research model (Fig. 1) highlighted the significance of mobile social media interactions in accumulating diverse social network ties, through the active engagement with health information (i.e., liking, sharing, and commenting on the content). Most importantly, this study's findings shed light on the roles of bonding and bridging social capital, linking different dimensions of health information engagement to enhanced psychological well-being.

Table 4 Significant Indirect Effects to Psychological Well-Being at a 95\% CI

\begin{tabular}{llll}
\hline & Indirect effect & Lower CI & Upper CI \\
\hline Like $\rightarrow$ Bonding social capital & $.036^{* *}(.069)$ & .018 & .062 \\
$\begin{array}{l}\text { Comment } \rightarrow \text { Bonding social } \\
\text { capital }\end{array}$ & $.034^{* *}(.066)$ & .019 & .054 \\
$\begin{array}{l}\text { Like } \rightarrow \text { Bridging social } \\
\text { capital }\end{array}$ & $.140^{* * *}(.278)$ & .095 & .191 \\
$\begin{array}{l}\text { Share } \rightarrow \text { Bridging social } \\
\text { capital }\end{array}$ & $.064^{* *}(.106)$ & .017 & .116 \\
$\begin{array}{l}\text { Comment } \rightarrow \text { Bridging social } \\
\text { capital }\end{array}$ & $.054^{* *}(.104)$ & .019 & .090 \\
\hline
\end{tabular}

Numbers in parentheses are standardized estimates. Path bootstrapped at 5,000 resamples. $\mathrm{CI}=$ confidence interval. $N=522$

${ }^{*} p<.05 ; * * p<.01 ; * * * p<.001$
First of all, this study found that active engagement with health information is beneficial for maintaining emotionally close ties with family and friends as well as for accruing heterogeneous weaker ties with acquaintances and even strangers, providing diverse information and broadening worldviews. Active engagement with heath information significantly predicted both bonding and bridging social capital, above and beyond social demographics, general WeChat usage, intensity, and network size. This demonstrates that the uses of unique affordances serve as distinct forms of investment in social interaction; the relationships are not artifacts of or confounded with general social media usage [21]. It also supports the argument that communication technology like WeChat or Facebook alone is often not sufficient to develop one's stock of social capital [30]. That is, the users' engagement behaviors, the activities that are afforded by the specific features on the platform, are the key to understanding how their networks are developed.

In addition, the different respective coefficients between different affordances' use and social capital revealed that mobile social media use has varying associations with the two forms of social capital, bonding and bridging, depending on what kind of feature is used, confirming previous studies (e.g., [6,21]). Specifically, the affordance of the "Like" button exerted the strongest power in cultivating both bonding and bridging social capital in our research model. Although some scholars have demonstrated that one-to-one composed communication (i.e., commenting, posting, and messaging) is more effective in increasing tie strength than one-click actions such as liking $[5,6]$, our results highlighted the significance of liking behavior as a type of directed communication [7]. Liking targets a particular friend or post, signaling the importance of the relationship and deeming it meaningful and valuable enough to merit an action, which is a good way to maintain and deepen relationships. More importantly, the disparate results may be partly due to the different media and the contexts involved as this study investigated particular social media use in a health context, while previous studies (e.g., [5, 6]) adopted a context-free approach. It is plausible that liking a health-related post not only functions as a social response to a particular friend's social media content signaling one's attention but also implies additional informative meanings such as a recommendation and advocacy of certain healthcare/lifestyle behaviors given the prevalence of health education messages on WeChat [88]. For example, a content analysis of WeChat health information found that messages containing a high level of efficacy (e.g., high effectiveness of the recommended behaviors to avoid hazards) received a greater number of Likes [14]. Therefore, considering that the nature and the effect of the communication are hard to isolate from the content of the communication, it is essential to take the communication context (e.g., specific affordances 
and content that users engaged with) into account so that theories can become more robust.

Moreover, the results found that active engagement with health information, via liking and sharing on WeChat, was a stronger predictor of bridging social capital than bonding social capital. This result is interesting but not surprising. On the one hand, a user's liking and sharing health-related information on WeChat can be seen as gatekeeping behaviors imbuing users with a sense of agency and a sense of community [65, 69]. Specifically, considering that the act of clicking a "Like" on a health-related post is displayed publicly, it is an explicit recommendation or approval of a post pointing to certain cues (e.g., "it is worth reading"). Thus, a user who clicks "Like" on a health post acts as a source in his/her WeChat community, enhancing their involvement in a broader community. Similarly, through sharing certain health-related information, a user makes a conscious decision to increase its visibility and influence by allowing it to be viewed by others within one's network of friends. This behavior also serves as an outlet for users to act as a gatekeeper for others, leading up to their sense of community [65], which is a core component of bridging social capital [61]. Supporting this argument, studies found that WeChat users' health information liking and sharing are largely driven by their inner needs of agency building in addition to social motivation [86], and users typically share the health content they deem is worthy to be read by a wider audience [35].

On the other hand, as suggested by media multiplexity [30], strong ties, by their very nature, offer more opportunities for face-to-face and synchronous communication through other affordances like voice/video calling; therefore, the asynchronous communication of active engagement on WeChat may serve an important role in managing weak ties when compared to strong ties. This finding makes sense in our daily lives. WeChat, or a similar mobile social media application, is one component of a diverse ecology of communication channels for strong ties. Family members and close friends have more frequent offline interactions. Thus, they do not need to rely on online engagement behaviors to keep in contact with each other as much as weak ties do $[5,21]$. This also implies that the interactive technology affordances that facilitate asynchronous social interactions provide necessary communication channels for weak ties to persist across time and geographic barriers. This result is in line with previous studies that focused on Western social media like Facebook [20] and extends the same conclusions to the Eastern context. The finding is not meant to underestimate the significant role social media plays in fortifying strong ties. Rather, this study cautions against a one-sided focus on either weak or strong ties in the relevant academic discussions.
In fact, in contrast to liking and sharing behaviors contributed more to bridging social capital, we found that commenting behavior did indeed exert a stronger association with bonding social capital. This finding is consistent with previous studies (e.g., $[5,8])$ and demonstrates that directed communication through message exchanges with friends plays a significant role in bonding social capital. Though people may have a large number of friends on social media, they tend to value a much smaller set of close friends and family with whom to have targeted and reciprocal communication [7]. Commenting involves more cognitive effort than liking and sharing $[1,6]$; therefore, it is not surprising that commenting behavior is slightly more associated with bonding social capital. The higher costs in time and effort signify the greater value placed upon strong-tie relationships [19].

Second, perceived bonding and bridging social capital were associated with enhanced psychological well-being, as our fourth and fifth hypotheses predicted they would be. In addition, the results revealed the mediating role of a person's perceived online social capital in establishing a relationship between social media use and psychological well-being. This finding supports Valkenburg and Peter's [77] demonstration that the positive association between mediated communication and greater life satisfaction is greatly dependent on the accumulation of high-quality relationships. In particular, the underlying pathways point out the key role of social capital, which also suggests that future social media research should be careful not to overemphasize the direct relationship between social media use and psychological well-being. The indirect effects of technology affordances on psychosocial outcomes indicate that the active engagement (liking, sharing, and commenting) facilitates the development of bonding and bridging social capital, which, in turn, empower the technology affordances to enhance psychological well-being.

Most notably, our results found that bridging social capital has a stronger relationship with one's psychological wellbeing than does the bonding social capital accumulated on social media. This can be partly explained by the operationalization of psychological well-being in the current study. Psychological well-being has been indicated as a typical proxy of eudaimonic well-being reflecting a more complex perspective on well-being with a focus on an individual's personal growth, autonomy, and full development of one's potential [34]. Accordingly, the measure of psychological well-being adopted in this study examined important aspects of human functioning including positive relations with others, feelings of competence, meaning, and purpose in life [18]. In this regard, core components of bridging social capital such as access to diverse opportunities, heterogeneous perspectives, and broader identities which typically brings more instrumental returns (e.g., diverse resources, reputation, status attainment) appear to have more to do with 
personal growth and flourishing [41, 42], thereby contributing more to psychological well-being compared to bonding social capital.

However, our finding is different from prior studies indicating a stronger relationship between bonding social capital and psychological well-being compared to bridging social capital $[10,13]$. Hence, the disparate results may be more concerned with the specific health context in the current study. It has been theorized that the engagement with social media content through interactivity affordances such as "Like," "Share," and "Comment" enables users to act as a source, which leads to their greater feelings of influence, autonomy, and control in one's network [69]. Empirical studies also found that such interactivity behaviors empower users through the sense of influence and sense of community $[53,54,65]$. In light of this, it appears that the active engagement, particularly in a health context in which the content can directly make a difference in one's health, is psychologically important by means of asserting one's influence and agency in the social network community (e.g., bring about changes for the welfare of the community as a whole by serving as gatekeepers or opinion leaders). Therefore, it is plausible that bridging social capital pertaining to broader identity and sense of broader community contributes more than bonding social capital to psychological well-being in our study context.

That said, our finding that both bonding and bridging social capital are conducive to psychological well-being extended the previous theoretical framework by demonstrating a dual-path approach [10] to well-being through both expressive strong ties and instrumental weak ties in the health context. This study responded to scholars' call (e.g., [79]) for more research on the role of weak ties in improving mental health, which has been overlooked in much of the previous research. Our results are resonant with previous research that found that wider social networks provide more diverse information and resources on job opportunities and the intellectual flexibility needed to deal with daily challenges [41, 42]. Such wider social networks can make people feel good, which may be beneficial for an individual's assessment of the meaningfulness and purpose of life.

\subsection{Theoretical and practical implications}

This study has provided empirical evidence to link social media affordances with psychological well-being via social capital. First, by examining the psychosocial outcomes of using the three specific affordances of "Like," "Share," and "Comment" in a health context, this study is unique in taking psychological aspects of technological affordances into health communication. The findings of this study identify specifically what type of networked resources (e.g., bonding and bridging) people perceive as more or less accessible in relation to their differential affordances usage in a health context, which ultimately makes a difference in their psychological well-being. As such, this study contributes to existing mobile social media literature and enriches researchers' theoretical understanding of why (e.g., underlying mechanisms) and how mobile social media use (e.g., what specific affordances that users engaged with) contribute to individuals' psychological well-being in which communication context (e.g., health-specific context). The findings provide important theoretical implications for future research examining the role of specific social media technology affordances and online social capital in people's psychosocial outcomes in emerging mobile social media.

Second, the finding that social capital (i.e., bonding social capital and bridging social capital) plays a significant mediating role helps to reconcile the inconsistent results from previous literature regarding the type of impact (positive, negative, or null) of social media on personal psychosocial outcomes. Our research has demonstrated that it is the underlying mechanism of social media affordances that explain how social media use is related to psychological well-being. This highlights that the psychological effects of social media technologies are not simply the result of overall social media usage but rather a product of the more complex process a person engages in, involving social structure and network dynamics, as the user selects features to actively engage his or her connections [10]. Future social media research should consider how specific features of the platform relate to one's social network development and connectedness, given that certain uses of social media (i.e., Like, Share, Comment) cannot influence one's well-being without fostering bonding and bridging social capital first.

Third, since our findings showed that both bonding and bridging social capital on WeChat are beneficial to users' psychological well-being, this study provides empirical evidence supporting the claim that $\mathrm{CMC}$ is an alternative, effective way to enhance individual well-being $[2,10,13$, $56,85]$. Lastly, scholars have indicated that weak ties are productive conduits for enhancing well-being because they expand a person's social networks by creating a wider range of critical social resources and information [41, 42]. The empirical results of this research, therefore, shed new light on the potential of employing mobile social media in the health context to mobilize weak ties and accumulate bridging social capital that is beneficial for instrumental returns and psychological well-being.

The conceptual lens of technology affordances and social capital also provides several practical implications that can inform mobile social media developers and health practitioners of harnessing mobile media to benefit users' social capital and their well-being. All the engagement behaviors examined in this study - liking, sharing, and commentingare tied to bonding and bridging social capital in the health 
context. Therefore, social media designers should consider creating incentives for users to engage with health-related information in ways that create opportunities for interactive communication. On the one hand, system designers can put more emphasis on platform interactivity. For instance, the features of "Like," "Share," and "Comment" can be embedded more pervasively to provide users with more action possibilities. On the other hand, health practitioners can create some campaigns for the mobile community (e.g., the hashtag \#myhealthyeating), calling for users' active participation by sharing photographs and videos and liking and commenting on others' posts. By linking similar discussions with hashtags and tags, users have more opportunities to interact with like-minded people, which is effective for building relationships.

In addition, because bridging social capital is beneficial for one's psychological well-being, future interface designs can be more effective at improving users' health and welfare by providing affordances or repeating opportunities to stimulate interaction (e.g., reminders, notifications, highlights) to maintain weak ties. For example, to nurture weak ties, interface designers can consider sending reminders (i.e., birthday) or notifications (i.e., group photograph) to prompt users to initiate conversations with old friends or acquaintances. Lastly, much of social media content, as well as the actions of liking, sharing, and commenting, has an ephemeral nature [7]. Posts are relatively transitory and quickly disappear from view in the archived Moment as new updates take their place. Social media designers can focus on mobile bookmarking and classification tools to organize users' engagement behaviors so that users can easily review their previous posts and related interactions. It would also be useful to provide users with an option of resurfacing prior engaged content or posts to propel more social interaction.

\subsection{Limitations and suggestions for future research}

Despite the significant implications, there are several limitations that need to be addressed. First, because of the nature of the cross-sectional data, it is ultimately impossible to resolve the causality issue of whether active engagement led to enhanced social capital. Although the proposed model with theoretical rationales was assumed based on previous literature, the relationship could still be reciprocal. Future research with longitudinal data would enrich our understanding of the directionality of these relationships. In addition, the convenience sampling used in this study may limit the generalizability of our findings. Future studies should consider employing probability sampling and nationally representative samples. Second, this study focused on two forms of social capital on WeChat; we did not measure offline social capital and networks due to the study's scope. Thus, it would be difficult to make a comparison of online and offline social capital or establish the effects of these types of capital on psychological well-being. This calls for future research to explore the dynamics between WeChat engagement behavior, social capital on and off WeChat, and psychological well-being. Third, though this study measured a user's WeChat network size, usage, and intensity as controls, other relevant variables (i.e., offline social network structure, psychological traits, and dispositions) may also exert significant influence on social capital and well-being. Future research could take other variables into account to unearth possible mediators and moderators that intervene in the relationship between active engagement on WeChat and social capital. Fourth, although this study sets user engagement on WeChat into a health context, certain health messages (e.g., containing strong emotional appeals) can provoke users' liking, sharing, and commenting behaviors. As such, it would be worthwhile to employ computational approaches (e.g., sentiment analysis) $[59,60]$ to delve into the potential content-related characteristics to provide a more nuanced understanding of user engagement in health contexts. Lastly, because of copyright issues, we were unable to access WeChat activity logs of our 522 survey participants, so we examined their active engagement with health information using self-reported measures. We encourage future researchers to replicate our study using activity logs from other mobile social media applications to further test the relationship between engagement behavior and psychosocial outcomes in other contexts.

\section{Conclusion}

Mobile social media have become an integral component of individuals' social networking and relationship development. This study provided an in-depth look at the social and psychological implications of WeChat in mobile-phonesaturated China, applying a variable-centered approach and the theoretical framework of social capital to the health context. WeChat, with diverse interactive functions, serves as a powerful platform for not just accumulating bonding social capital among close family and friends but also accruing bridging social capital, which is derived from looser connections. Notably, this study's findings have underscored the importance of actively engaging in one's online social networks, indicating that social capital is not simply generated by the sole presence of social networking technology. Rather, it is developed through lightweight interactions (i.e., small but intentional and meaningful efforts invested in relationships) [24], such as sharing health information, showing support by liking another person's post, or commenting on or replying to posts. A dual-path structure moves a user from mobile social media use to psychological well-being via bonding and bridging social capital. This structure sheds 
light on new directions for utilizing mobile social media as an alternative to achieve greater well-being through fortifying existing connections, expanding the scope of contacts, and offering emotional and informational social resources.

\section{Availability of data and material}

The datasets generated and/or analyzed during the current study are available from the corresponding author on reasonable request.

Funding This research did not receive any specific grant from funding agencies in the public, commercial, or not-for-profit sectors.

\section{Compliance with ethical standards}

Conflict of interest The authors declare no potential conflicts of interest with respect to the research, authorship, and/or publication of this article.

Ethical Approval This study has obtained ethics approval from the National University of Singapore Institutional Review Board. All procedures performed in the current study involving human participants were in accordance with the ethical standards of the National University of Singapore Institutional Review Board.

\section{References}

1. Alhabash, S., McAlister, A.R.: Redefining virality in less broad strokes: predicting viral behavioral intentions from motivations and uses of Facebook and Twitter. New Media Soc. 17, 13171339 (2015). https://doi.org/10.1177/1461444814523726

2. Ang, C.S., Talib, M.A., Tan, K.A., Tan, J.P., Yaacob, S.N.: Understanding computer-mediated communication attributes and life satisfaction from the perspectives of uses and gratifications and self-determination. Comput. Hum. Behav. 49, 20-29 (2015). https ://doi.org/10.1016/j.chb.2015.02.037

3. Bollen, K., Lennox, R.: Conventional wisdom on measurement: a structural equation perspective. Psychol. Bull. 110, 305-314 (1991). https://doi.org/10.1037/0033-2909.110.2.305

4. Brodie, R.J., Ilic, A., Juric, B., Hollebeek, L.: Consumer engagement in a virtual brand community: an exploratory analysis. J. Bus. Res. 66(1), 105-114 (2013). https://doi.org/10.1016/j.jbusr es.2011.07.029

5. Burke, M., Kraut, R.E.: Growing closer on Facebook: changes in tie strength through social network site use. In: Proceedings of the SIGCHI Conference on Human Factors in Computing Systems. ACM, pp. 4187-4196. (2014) https://doi.org/10.1145/25562 88.2557094

6. Burke, M., Kraut, R.E.: The relationship between Facebook use and well-being depends on communication type and tie strength. J. Comput. Mediat. Commun. 21, 265-281 (2016). https://doi. org/10.1111/jcc4.12162

7. Burke, M., Kraut, R.E., Marlow, C.: Social capital on Facebook: differentiating uses and users. In: Proceedings of the SIGCHI Conference on Human Factors in Computing Systems. ACM, pp.
571-580. (2011) https://doi.org/https://doi.org/10.1145/19789 42.1979023

8. Burke, M., Marlow, C., Lento, T.: Social network activity and social well-being. In: Proceedings of the SIGCHI Conference on Human Factors in Computing Systems. ACM, pp. 1909-1912. (2010), https://doi.org/10.1145/1753326.1753613

9. Carr, C.T., Wohn, D.Y., Hayes, R.A.: As social support: relational closeness, automaticity, and interpreting social support from paralinguistic digital affordances in social media. Comput. Hum. Behav. 62, 385-393 (2016). https://doi.org/10.1016/j. chb.2016.03.087

10. Chan, M.: Mobile phones and the good life: examining the relationships among mobile use, social capital and subjective well-being. New Media Soc. 17, 96-113 (2015). https://doi. org/10.1177/1461444813516836

11. Chan, M.: Digital communications and psychological wellbeing across the life span: examining the intervening roles of social capital and civic engagement. Telemat. Inform. 35(6), 1744-1754 (2018). https://doi.org/10.1016/j.tele.2018.05.003

12. Cheikh-Ammar, M., Barki, H.: The influence of social presence, social exchange and feedback features on SNS continuous use: the Facebook context. J. Organ. End User Comput. 28(2), 33-52 (2016). https://doi.org/10.4018/joeuc.2016040103

13. Chen, H.T., Li, X.: The contribution of mobile social media to social capital and psychological well-being: examining the role of communicative use, friending and self-disclosure. Comput. Hum. Behav. 75, 958-965 (2017). https://doi.org/10.1016/j. chb.2017.06.011

14. Chen, L., Yang, X., Fu, L., Liu, X., Yuan, C.: Using the extended parallel process model to examine the nature and impact of breast cancer prevention information on mobile-based social media: content analysis. JMIR mHealth uHealth 7(6), e13987 (2019). https://doi.org/10.2196/13987

15. China Internet Network Information Center (2020). The 46th China statistical report on internet development. http://www. cac.gov.cn/2020-09/29/c_1602939918747816.htm Accessed 10 October 2020

16. Chiu, C., Ip, C., Silverman, A.: Understanding social media in China. Retrieved from https://www.mckinsey.com/businessfunctions/marketing-and-sales/our-insights/understanding-socia 1-media-in-china\# Accessed April 08, 2020

17. Cinelli, M., Quattrociocchi, W., Galeazzi, A., Valensise, C.M., Brugnoli, E., Schmidt, A.L. et al.: The covid-19 social media infodemic. ArXiv Preprints. Retrieved from https://arxiv.org/ abs/2003.05004 Accessed May 20, 2020

18. Diener, E.D., Wirtz, D., Biswas-Diener, R., Tov, W., Kim-Prieto, C., Choi, D.W., Oishi, S.: New measures of well-being. In: Diener, E.D. (ed.) Assessing well-being, pp. 247-266. Springer, New York (2009)

19. Donath, J.: Signals in social supernets. J. Comput. Mediat. Commun. 13, 231-251 (2007). https://doi.org/10.111 1/j.1083-6101.2007.00394.x

20. Ellison, N.B., Steinfield, C., Lampe, C.: The benefits of Facebook "friends:" Social capital and college students' use of online social network sites. J. Comput. Mediat. Commun. 12, 11431168 (2007). https://doi.org/10.1111/j.1083-6101.2007.00367.x

21. Ellison, N.B., Vitak, J., Gray, R., Lampe, C.: Cultivating social resources on social network sites: Facebook relationship maintenance behaviors and their role in social capital processes. J. Comput. Mediat. Commun. 19, 855-870 (2014). https://doi. org/10.1111/jcc4.12078

22. Fornell, C., Larcker, D.F.: Structural equation models with unobservable variables and measurement error: Algebra and statistics. J. Mark. Res. 18(3), 382-388 (1981). https://doi. org/10.2307/3151335 
23. Gan, C.: Understanding WeChat users' liking behavior: an empirical study in China. Comput. Hum. Behav. 68, 30-39 (2017). https://doi.org/10.1016/j.chb.2016.11.002

24. Gerlitz, C., Helmond, A.: The like economy: social buttons and the data-intensive web. New Media Soc. 15(8), 1348-1365 (2013). https://doi.org/10.1177/1461444812472322

25. Granovetter, M.: The strength of weak ties. Am. J. Sociol. 78, 1360-1379 (1973). https://doi.org/10.1086/225469

26. Granovetter, M.: The strength of weak ties: a network theory revisited. Sociol. Theory 1, 201-233 (1983). https://doi. org/10.2307/202051

27. Guo, Y., Li, Y., Ito, N.: Exploring the predicted effect of social networking site use on perceived social capital and psychological well-being of Chinese international students in Japan. Cyberpsychol. Behav. Soc. Netw. 17, 52-58 (2014). https://doi.org/10.1089/ cyber.2012.0537

28. Hayes, A.F.: Introduction to mediation, moderation, and conditional process analysis: A regression-based approach. The Guilford Press, New York (2013)

29. Hayes, R.A., Carr, C.T., Wohn, D.Y.: One click, many meanings: Interpreting paralinguistic digital affordances in social media. J. Broadcast. Electron. Media 60(1), 171-187 (2016). https://doi. org/10.1080/08838151.2015.1127248

30. Haythornthwaite, C.: Social networks and Internet connectivity effects. Inf. Commun. Soc. 8, 125-147 (2005). https://doi. org/10.1080/13691180500146185

31. Helliwell, J.F., Putnam, R.D.: The social context of well-being. Philos. Trans. R. Soc. B 359, 1435-1446 (2004). https://doi. org/10.1098/rstb.2004.1522

32. Huang, C.: Internet use and psychological well-being: a metaanalysis. Cyberpsychol. Behav. Soc. Netw. 13, 241-249 (2010). https://doi.org/10.1089/cpb.2009.0217

33. Hu, L.T., Bentler, P.M.: Cutoff criteria for fit indexes in covariance structure analysis: Conventional criteria versus new alternatives. Struct. Equ. Modeling 6, 1-55 (1999). https://doi. org/10.1080/10705519909540118

34. Huta, V.: An overview of hedonic and eudaimonic well-being concepts. In: Reinecke, L., Oliver, M.B. (eds.) The Routledge handbook of media use and well-being: International perspectives on theory and research on positive media effects, pp. 14-33. Routledge, New York (2016)

35. Kaur, W., Balakrishnan, V., Rana, O., Sinniah, A.: Liking, sharing, commenting and reacting on Facebook: user behaviors' impact on sentiment intensity. Telemat. Inform. 39, 25-36 (2019). https:// doi.org/10.1016/j.tele.2018.12.005

36. Khan, M.L.: Social media engagement: what motivates user participation and consumption on YouTube? Comput. Hum. Behav. 66, 236-247 (2017). https://doi.org/10.1016/j.chb.2016.09.024

37. Ko, H.C., Kuo, F.Y.: Can blogging enhance subjective well-being through self-disclosure? Cyberpsychol. Behav. 12(1), 75-79 (2009). https://doi.org/10.1089/cpb.2008.016

38. Ledbetter, A.M., Mazer, J.P., DeGroot, J.M., Meyer, K.R., Mao, Y., Swafford, B.: Attitudes toward online social connection and self-disclosure as predictors of Facebook communication and relational closeness. Commun. Res. 38, 27-53 (2011). https://doi. org/10.1177/0093650210365537

39. Lee, S., Chung, J.E., Park, N.: Network environments and wellbeing: An examination of personal network structure, social capital, and perceived social support. Health Commun. 33, 22-31 (2018). https://doi.org/10.1080/10410236.2016.1242032

40. Lee, S.Y., Hansen, S.S., Lee, J.K.: What makes us click "like" on Facebook? Examining psychological, technological, and motivational factors on virtual endorsement. Comput. Commun. 73, 332-341 (2016). https://doi.org/10.1016/j.comcom.2015.08.002
41. Lin, N.: Building a network theory of social capital. In: Lin, N., Cook, K., Burt, R.S. (eds.) Social capital theory and research, pp. 1-28. Routledge, Boca Raton (2001)

42. Lin, N.: Social capital: a theory of social structure and action. Cambridge University Press, Cambridge (2001)

43. Liu, M., Yan, Y., Sun, Y.: Exploring health information sharing behavior among Chinese older adults: a social support perspective. Health Commun. 34(14), 1824-1832 (2019). https://doi. org/10.1080/10410236.2018.1536950

44. Lup, K., Trub, L., Rosenthal, L.: Instagram\# instasad?: exploring associations among instagram use, depressive symptoms, negative social comparison, and strangers followed. Cyberpsychol. Behav. Soc. Netw. 18, 247-252 (2015). https://doi. org/10.1089/cyber.2014.0560

45. Lustria, M.L.A.: Can interactivity make a difference? effects of interactivity on the comprehension of and attitudes toward online health content. J. Assoc. Inf. Sci. Technol. 58(6), 766776 (2007). https://doi.org/10.1002/asi.20557

46. Maksl, A., Young, R.: Affording to exchange: social capital and online information sharing. Cyberpsychol. Behav. Soc. Netw. 16, 588-592 (2013). https://doi.org/10.1089/cyber.2012.0430

47. Malinowski, B.: Phatic communion. In: Laver, J., Hutchinson, S. (eds.) Communication in face-to-face interaction, pp. 146-152. Penguin Books, Harmondsworth (1972)

48. Marino, C., Gini, G., Vieno, A., Spada, M.M.: The associations between problematic Facebook use, psychological distress and well-being among adolescents and young adults: a systematic review and meta-analysis. J. Affect. Disord. 226, 274-281 (2017). https://doi.org/10.1016/j.jad.2017.10.007

49. Miller, V.: New media, networking and phatic culture. Convergence 14(4), 387-400 (2008). https://doi.org/10.1177/13548 56508094659

50. Moorhead, S.A., Hazlett, D.E., Harrison, L., Carroll, J.K., Irwin, A., Hoving, C.: A new dimension of health care: systematic review of the uses, benefits, and limitations of social media for health communication. J. Med. Internet Res. 15(4), e85 (2013). https://doi.org/10.2196/jmir.1933

51. Nass, C., Mason, L.: On the study of technology and task: a variable-based approach. In: Fulk, J., Steinfield, C. (eds.) Organizations and communication technology, pp. 46-67. Sage, Newbury Park (1990)

52. Norman, D.A.: Affordance, conventions, and design. Interactions 6, 38-43 (1999). https://doi.org/10.1145/301153.301168

53. Oeldorf-Hirsch, A., High, A.C., Christensen, J.L.: Count your calories and share them: health benefits of sharing mHealth information on social networking sites. Health Commun. 34(10), 1130-1140 (2019). https://doi.org/10.1080/10410 236.2018.1465791

54. Oeldorf-Hirsch, A., Sundar, S.S.: Posting, commenting, and tagging: effects of sharing news stories on Facebook. Comput. Hum. Behav. 44, 240-249 (2015). https://doi.org/10.1016/j. chb.2014.11.024

55. O'Sullivan, P.B., Carr, C.T.: Masspersonal communication: a model bridging the mass-interpersonal divide. New Media Soc. 20(3), 1161-1180 (2018). https://doi.org/10.1177/1461444816 686104

56. Pang, H.: Exploring the beneficial effects of social networking site use on Chinese students' perceptions of social capital and psychological well-being in Germany. Int. J. Intercult. Relat. 67, 1-11 (2018). https://doi.org/10.1016/j.ijintrel.2018.08.002

57. Park, N., Jin, B., Jin, S.A.A.: Effects of self-disclosure on relational intimacy in Facebook. Comput. Hum. Behav. 27, 19741983 (2011). https://doi.org/10.1016/j.chb.2011.05.004

58. Petersen, C., Johnston, K.A.: The impact of social media usage on the cognitive social capital of university students. Informing Sci. 18, 1-31 (2015) 
59. Petz, G., Karpowicz, M., Fürschuß, H., Auinger, A., Stř́iteský, V., Holzinger, A.: Computational approaches for mining user's opinions on the Web 2.0. Inf. Process. Manag. 50(6), 899-908 (2014). https://doi.org/10.1016/j.ipm.2014.07.005

60. Petz, G., Karpowicz, M., Fürschuß, H., Auinger, A., Stř́iteský, V., Holzinger, A.: Opinion mining on the Web 2.0 - Characteristics of user generated content and their impacts. In: International Workshop on Human-Computer Interaction and Knowledge Discovery in Complex, Unstructured, Big Data. Springe, Berlin, Heidelberg, pp 35-46, (2013) https://doi.org/10.1007/978-3-642-39146-0_4

61. Putnam, R.: Bowling alone: the collapse and revival of American community. Simon and Schuster, New York (2000)

62. Rubin, A.M.: The uses-and-gratifications perspective of media effects. In: Bryant, J., Oliver, M.B. (eds.) Media effects: advances in theory and research, 3rd edn., pp. 165-184. Routledge, New York (2009)

63. Sagioglou, C., Greitemeyer, T.: Facebook's emotional consequences: why Facebook causes a decrease in mood and why people still use it. Comput. Hum. Behav. 35, 359-363 (2014). https ://doi.org/10.1016/j.chb.2014.03.003

64. Smock, A.D., Ellison, N.B., Lampe, C., Wohn, D.Y.: Facebook as a toolkit: a uses and gratification approach to unbundling feature use. Comput. Hum. Behav. 27(6), 2322-2329 (2011). https://doi. org/10.1016/j.chb.2011.07.011

65. Stavrositu, C., Sundar, S.S.: Does blogging empower women? Exploring the role of agency and community. J. Comput.Mediat. Commun. 17(4), 369-386 (2012). https://doi.org/10.11 11/j.1083-6101.2012.01587.x

66. Steinfield, C., Ellison, N.B., Lampe, C.: Social capital, selfesteem, and use of online social network sites: a longitudinal analysis. J. Appl. Dev. Psychol. 29, 434-445 (2008). https://doi. org/10.1016/j.appdev.2008.07.002

67. Strekalova, Y.A.: Health risk information engagement and amplification on social media: news about an emerging pandemic on Facebook. Health Educ. Behav. 44(2), 332-339 (2017). https:// doi.org/10.1177/1090198116660310

68. Sum, S., Mathews, M.R., Pourghasem, M., Hughes, I.: Internet technology and social capital: how the Internet affects seniors' social capital and wellbeing. J. Comput. Mediat. Commun. 14, 202-220 (2008). https://doi.org/10.1111/j.1083-6101.2008.01437 . $\mathrm{x}$

69. Sundar, S.S.: Self as source: agency and customization in interactive media. In: Konijn, E.A., Utz, S., Tanis, M., Barnes, S.B. (eds.) Mediated interpersonal communication, pp. 58-74. Routledge, New York (2008)

70. Sundar, S.S.: Media effects 2.0: social and psychological effects of communication technologies. In: Nabi, R.L., Oliver, M.B. (eds.) The SAGE handbook of media processes and effects, pp. 545-560. Sage, Thousand Oaks (2009)

71. Sumner, E.M., Ruge-Jones, L., Alcorn, D.: A functional approach to the Facebook Like button: an exploration of meaning, interpersonal functionality, and potential alternative response buttons. New Media Soc. 20(4), 1451-1469 (2018). https://doi. org/10.1177/1461444817697917

72. Tichon, J.G., Shapiro, M.: The process of sharing social support in cyberspace. Cyberpsychol. Behav. 6(2), 161-170 (2003). https ://doi.org/10.1089/109493103321640356

73. The Statistics Portal (2020) Number of monthly active WeChat users from 2nd quarter 2010 to 3rd quarter 2020 (in millions) Retrieved from https://www.statista.com/statistics/255778/numbe r-of-active-wechat-messenger-accounts/ Accessed 04 January 2021

74. Tong, S., Walther, J.B.: Relational maintenance and CMC. In: Wright, K.B., Webb, L.M. (eds.) Computer-mediated communication in personal relationships, pp. 98-118. Peter Lang, New York (2011)

75. Tufekci, Z.: Grooming, gossip, Facebook and MySpace: What can we learn about these sites from those who won't assimilate? Inf. Commun. Soc. 11, 544-564 (2008). https://doi.org/10.1080/13691 180801999050

76. Utz, S.: The function of self-disclosure on social network sites: not only intimate, but also positive and entertaining self-disclosures increase the feeling of connection. Comput. Hum. Behav. 45, 1-10 (2015). https://doi.org/10.1016/j.chb.2014.11.076

77. Valkenburg, P.M., Peter, J.: Social consequences of the Internet for adolescents: a decade of research. Curr. Dir. Psychol. Sci. 18(1), 1-5 (2009). https://doi.org/10.1111/j.1467-8721.2009.01595.x

78. Vergeer, M., Pelzer, B.: Consequences of media and Internet use for offline and online network capital and well-being. a causal model approach. J. Comput. Mediat. Commun. 15, 189-210 (2009). https://doi.org/10.1111/j.1083-6101.2009.01499.x

79. Wang, H., Chua, V., Stefanone, M.A.: Social ties, communication channels, and personal well-being: a study of the networked lives of college students in Singapore. Am. Behav. Sci. 59, 1189-1202 (2015). https://doi.org/10.1177/0002764215580590

80. Wang, J.L., Jackson, L.A., Gaskin, J., Wang, H.Z.: The effects of Social Networking Site (SNS) use on college students' friendship and well-being. Comput. Hum. Behav. 37, 229-236 (2014). https ://doi.org/10.1016/j.chb.2014.04.051

81. Wang, W., Zhuang, X., Shao, P.: Exploring health information sharing behavior of Chinese elderly adults on WeChat. Healthcare. 8(3), 207-222 (2020). https://doi.org/10.3390/healthcare8030207

82. Wei, R., Huang, J., Zheng, P.: Use of mobile social apps for public communication in China: gratifications as antecedents of reposting articles from WeChat public accounts. Mob. Media Commun. 6, 108-126 (2017). https://doi.org/10.1177/2050157917728100

83. Williams, D.: On and off the 'Net: scales for social capital in an online era. J. Comput. Mediat. Commun. 11, 593-628 (2006). https://doi.org/10.1111/j.1083-6101.2006.00029.x

84. Wright, K., Craig, E., Cunningham, C., Igiel, M., Ploeger, N.: Will you (still) be my friend? Computer-mediated relational maintenance on Facebook. com. In: 94th Annual Meeting of the National Communication Association, San Diego, CA, (2008)

85. Zhan, L., Sun, Y., Wang, N., Zhang, X.: Understanding the influence of social media on people's life satisfaction through two competing explanatory mechanisms. Aslib. J. Inform. Manag. 68, 347-361 (2016). https://doi.org/10.1108/ajim-12-2015-0195

86. Zhang, L., Jung, E.H.: WeChatting for health: an examination of the relationship between motivations and active engagement. Health Commun. 34(14), 1764-1774 (2019). https://doi. org/10.1080/10410236.2018.1536942

87. Zhang, L., Jung, E.H., Chen, Z.: Modeling the pathway linking health information seeking to psychological well-being on WeChat. Health Commun. 5(9), 1101-1112 (2020). https://doi. org/10.1080/10410236.2019.1613479

88. Zhang, X., Wen, D., Liang, J., Lei, J.: How the public uses social media WeChat to obtain health information in China: a survey study. BMC Med. Inform. Decis. Mak. 17, 72-79 (2017). https:// doi.org/10.1186/s12911-017-0470-0

Publisher's Note Springer Nature remains neutral with regard to jurisdictional claims in published maps and institutional affiliations. 